\title{
INTEGRATED COST MODEL FOR IMPROVING THE PRODUCTION IN COMPANIES
}

\author{
DOI: 10.12776/QIP.V18I2.379
}

\author{
ZUZANA HAJDUOVÁ
}

Received 2 September 2014, Revised 17 October 2014, Accepted 22 November 2014

\section{INTRODUCTION}

Statistical methods represent integral part of the improvement. Not only in the process of diagnosis of error origin and management of experiments. These methods are more and more used to estimate the economic improvement attributes, i.e. expected costs in connection with the improvement of processes or profits upon accomplishment of improvement goals.

Based on standards ISO 9001, ISO 14001 and OHSAS 18000 businesses build systems approach to solve any problems related to their business. Any management system that performs the function of the nervous system of healthy business should contain its own structure - a subsystem focused on continuous improvement - provided according to the basic principle of teamwork implementation, project partners and strategic improvement teams, linked to managing structures.

Integrated Management System (IMS) arises from the need of businesses to align, combine or merge separately implemented management systems. Integration is carried out because of systematic solution of stakeholders' needs. It represents a considered process of developing management structures, which enables more systematic management of key requirements of all sides involved. Integration provides the infrastructure to manage and improve in different dimensions. It can highlight the areas that would otherwise remain ignored, such as health and safety and social responsibility. As part of the main business management system, stakeholders' requirements exceed normal agenda and are extended. Integration therefore subordinates certain demands and on the other hand it tries to fulfil other. Unlike non-integrated systems, integrated system systematically collects requirements of stakeholders in order to design organizational processes accordingly. Output is realized through the integrated audits and subsequently permanent integrated improvements are performed for system optimization (Asif et al, 2010). 
Development of one integrated management system could also limit the shortcomings between different MSs and minimize the resources needed to develop, implement and maintain separate systems (McDonald et al., 2003). Literature dealing with the integration of MS can be divided into three streams:

First stream: This literature deals with the basic concepts related to the integrated management system (IMS). IMS is designed as one set of interrelated processes that share common unique human, informative, material, infrastructural and financial resources to achieve the set of targets linked to the satisfaction of various stakeholders involved (Karapetrovic, 2003). Literature in this stream elaborates the concept of integration and provides a basis for further research on IMS. Significant works are published by Griffith (2000), Karapetrovic (2003), Karapetrovic and Willborn (1998), and Wilkinson and Dale (1999, 2001, 2002).

The second stream: The second stream of the literature focuses on further exploration of IMS, primarily to demonstrate the importance of IMS. These studies are generally empirical in nature and come mostly from case studies, see e.g. Douglas and Glen (2000), Jørgensen et al. (2006), Salomone (2008), and Zutshi and Sohal (2005). This stream of literature, moreover, also focuses on certain issues, challenges and factors that influence the integration of management systems. As well it points out a series of strategic, tactical and operational benefits of integration, see e.g. McDonald et al. (2003) and Zutshi and Sohal (2005). Although the main focus is on the benefits of integration, it does not discuss the integration process itself, nor does it provide an understanding of how it is possible to achieve benefits through the integration.

The third stream: This literature focuses on practical approaches for implementing the integration, focusing on strategy and process of integration as well as the degree of integration. Examples are Karapetrovic and Jonker (2003) and Rocha et al. (2007).

\section{METHODOLOGY}

The paper describes the merits and application of quantitative methods in practical conditions of the manufacturing process.

Statistics can be described as the science of collective phenomena and variability in appearance. Use of statistical methods is universal. In either direct or indirect form is part of everyday practice. Statistical methods (SM) as an important instrument of quality management is now undisputed. The implementation of standards such as the ISO 9001: 2000, VDA 6.1, QS 9001, ISO TS 16949, TQM model, Lean Management Systems and Six Sigma, the competitiveness of businesses improves also in our conditions, especially in the field of quality, environment, safety etc. In the publication we present in detail all the methods of inductive statistics. It outlines only the way experiments were designed and evaluated. 


\section{Mathematical expression of the integrated improvement cost model}

Problem of mathematical expression of proposed cost model of an integrated improvement lies in the large number of factors, which, in non-trivial way affects the cost. Model, which would include all of these factors, could (although it would be a sufficiently precise) not be, due to its complexity, well interpretable and hence would be useless in practice. For this reason we decided to create three-dimensional cost model which is based on two-dimensional schemes and is complemented by a third dimension representing time. Mathematically, therefore, the shape of the cost function can be written in the following expression:

$$
N=f\left(\theta, t, N_{I}\right)+\varepsilon
$$

where

$$
N_{I}=g\left(N_{Q}, N_{E}, N_{S}\right)
$$

where

$N$ represents the total cost function,

$\varepsilon$ residual component of model, since it has stochastic character,

$t$ represents time but through time into the cost function the changes are often mapped discontinuously in temperature and other factors which do not describe explicitly in the model but in real times by a significantly changes.

$\theta$ major improvement parameter, i.e. parameter whose improvement represents the overall improvement of project. As in the case of time, cost function reflects different changes of threshold values for certain limit boundary values of that parameter $\theta$

$f($.$) represents the functional relationship between the examined parameter of$ improvement $\theta$ in time $t$ and amount of estimated costs for an integrated approach to improvement,

$N_{Q}$ represent the costs of continuous qualityimprovement for a given parameter $\theta$ at a given time $\mathrm{t}$

$N_{E} \quad$ represents the cost of an environment for a given parameter $\theta$ at a given time $t$

$N_{S}$ represents the security costs for a given parameter $\theta$ at a given time $t$

$N_{I} \quad$ represents the cost of an integrated improvement at a specific time $t$ for the level of parameter $\theta$

$g($.) represents a functional relationship, describes how different types of costs affect the total cost of improving in an integrated approach of evaluation 
It is very often about simple counting in so-called additive models. Often, however, the function describes the complex synergistic interaction effects of mentioned factors.

Since this is a stochastic process, the quality of the model is verified by using residual component $\varepsilon$. Particular functions $f$ and $g$ are determined by a regression analysis based on available data. Translating the data obtained to the timeline allows the prediction of the expected development, i.e. expected costs for a given degree of attainment of the parameter at the time. Please note that the relevant prediction must also be considered with discontinuous shifts caused by the socalled re-engineering, various environmental changes, etc.

\section{CASE STUDY}

Company $\mathrm{Cu}$ Drôt, a.s. has a long tradition in the processing of copper. The first mention of copper in the region appeared on European markets in 80's of 14th century. During the World War I and II the production of copper decreased and consequently totally stopped. After the end of World War II the production of copper was renewed, which was made from copper waste that has accumulated during the war. This method had been profitable; therefore it was necessary to use new technologies and equipment. Stages of development:

$1^{\text {st }}$ Stage: Production of copper wire of diameter of $8 \mathrm{~mm}$ takes place on the line installed in 1993 by the Italian company Continuous - Properzi. It is a line with a small nominal capacity (30,000 tonnes per year), intended for the manufacture of wire of medium to lower level. Investment costs of improvement at this stage represented approximately 500,000 EUR.

$2^{\text {nd }}$ Stage: In 2002 there was the entry of foreign capital into the company and again in 2004 company was incorporated into international group of companies thus there were new assumptions for the creation of appropriate conditions for further development and growth of the company. This cooperation led to the modernization of the blast furnace and to construction of lines for the production of copper anodes. The conclusions of this research work are carried out under the name of Experiment 2. Investment costs of improving represent approximately 1,000,000 EUR.

$\mathbf{3}^{\text {rd }}$ Stage: An acceptable option how to significantly increase the quality of the wire was a complete up-grade of lines, which means upgrade or replacement of its essential components. Secondary rather negligible impact of such modernization is also an increase in annual production capacity. Line after the implementation of upgrade will be able to produce annually about 50000 tonnes of wire in higher quality.

Changes occur in the following nodes:

- intensification of burner system, 
- new casting machine,

- new automatic scissors,

- new cleaning unit (high profile spritzer)

- new final rolling stool,

- new pickling (reduction zone),

- intensification of existing cooling tunnel.

Expected investment costs amounted were approximately 2.2 million EUR.

\section{RESULTS - ESTIMATION OF THE COMPONENTS OF THE INTEGRATED IMPROVEMENT COST FUNCTION}

As we observed in our study, the main parameter of the integrated improvement, in experiments also called response, was the oxide layer on the surface of the wire. In mathematical terms, it is a parameter that in relation (1) is marked $\theta$. In next step cost functions, so called cost of an integrated improvement are eliminated and are marked as $N_{i}$. The costs of the integrated improvement, as shown in the second formula, represent a function of the costs of continuous quality improvement, safety, environment, as well as other attributes influencing the final cost function.

Development of the additive model of an integrated improvement will be based on the following attributes:

- Costs of continuous quality improvement.

- The cost of the environment.

- OSH costs (Occupational safety and health).

\section{1) Costs of continuous quality improvement}

Estimation of costs is based on two experiments realized by the authors. The first was to improve the oxide layer at the level of $3000 \AA$ to $8000 \AA$ (Experiment 1 , 2001). After a subsequent change in technology (2009) Experiment 2 was performed, which was aimed to reduce the oxide layer at the level of $700 \AA$ to $900 \AA$ (phase 2). Another basis for estimating the cost of continuous quality improvement has been project of line modernization (in 2010) with an expected reduction of oxide layer at the level of about $200 \AA$ (phase 3 ).

Estimation of that cost curve is shown in Fig. 1, and is executed with three cost curves for each stage of improvement. 


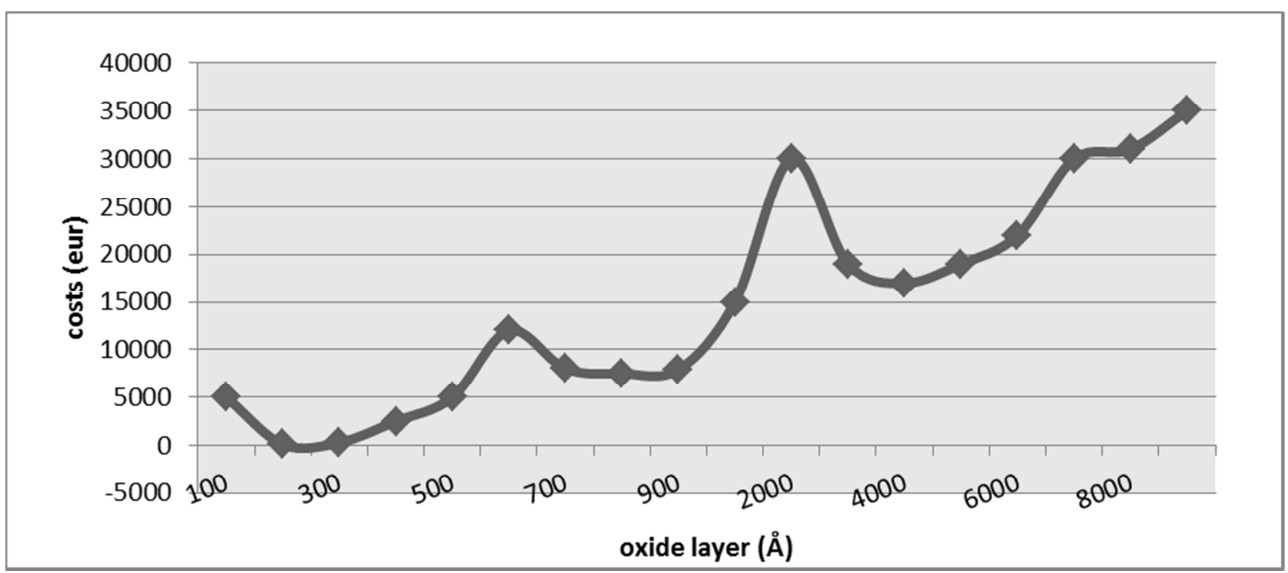

Figure 1 - Costs of continuous quality improvement (Source: own processing)

Component of the graph from $800 \AA$ to $1000 \AA$ is estimated using Experiment 2 The lowest costs are achieved with the value of $840 \AA$. Reducing the level of oxide layer at a given stage of technology by optimizing process parameters, again increas the cost of improvement to the level of approximately $700 \AA$, which is the highest value of the cost. On the other hand, the value from $900 \AA$ to $1100 \AA$ is achievable with this technology and general setting of all parameters. Section of cost curve at the level of $200 \AA$ is based on assumptions of new technology supplier. The graph shows that the sensitivity to parameter setting in the latest technology is the smallest.

\section{2) The cost of the environment}

The costs of the environment are exclusively those that occur at the customer. Given the specifics of the process of drawing copper wire for cold, cost of environment within the material flow incur at the customer. While copper dust generated during pulling of cables at the level of surface oxides up to $200 \AA$ is negligible, the increase is almost linear throughout the progress. The costs incurred in connection with extraction of copper followed by filtering dust and copper waste disposal (waste, as we have already mentioned, represents the raw material for the production of copper wire and therefore the cost of waste disposal consists mainly of transport and logistics). The resulting curve of the cost of environment is shown in Fig. 2.

\section{3) Costs of OSH}

These are costs that arise again at the customer in connection with the formation of copper dust when pulling copper wire at cold. This causes an increase of costs described in Fig. 3. 


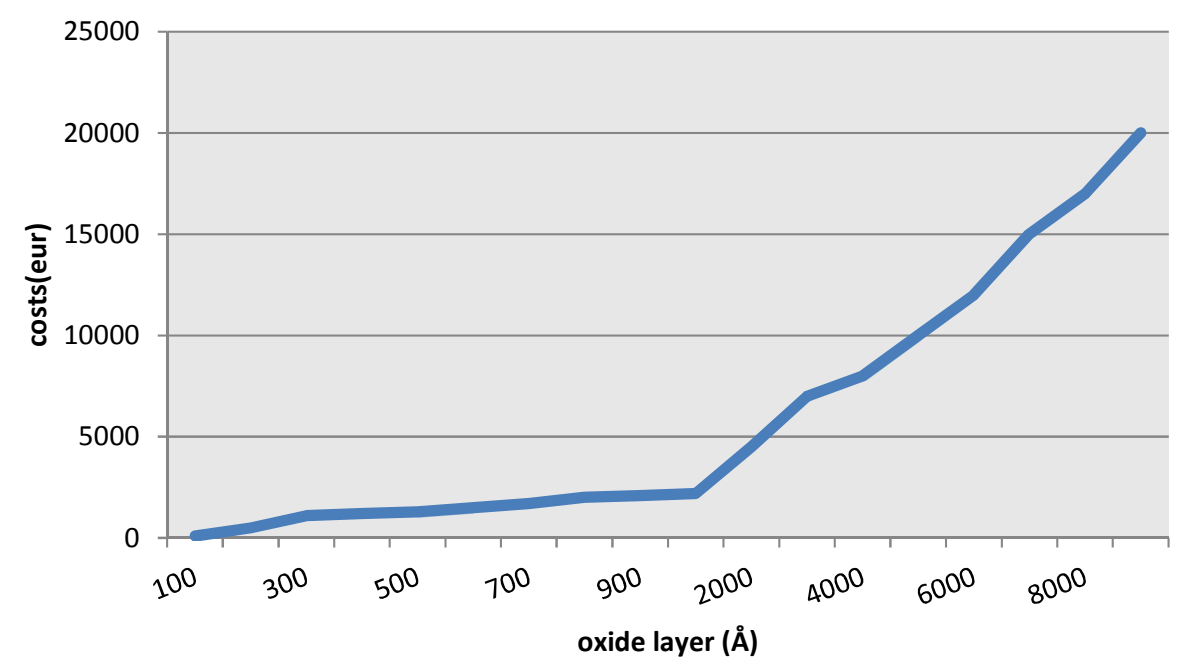

Figure 2 - The costs of environment (Source: own processing)

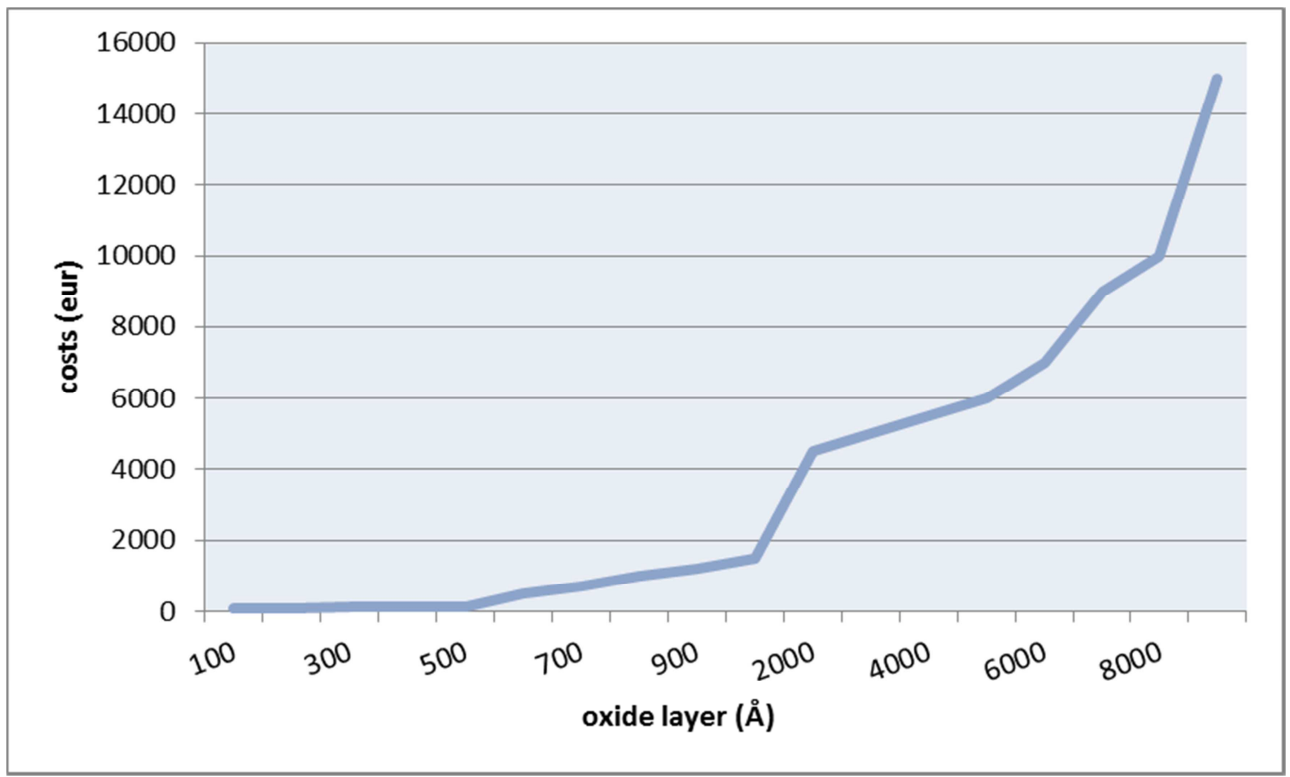

Figure 3 - Costs of OSH (Source: own processing)

\section{4) Investment costs of the technology}

Estimation of investment cost of technology is based on an estimate of direct investments, in connection with the various stages of re-engineering, recalculated to 1 tonne of expected production (the calculation is used mainly in stage 3, when the estimated investment costs are 2,200,000 EUR, but there is also expected an 
increase in the production volume from 30,000 up to 50,000 tonnes). In the last two stages, the expected value of production was 30,000 tonnes. Mentioned conversion explains the curve progress described in Fig. 4.

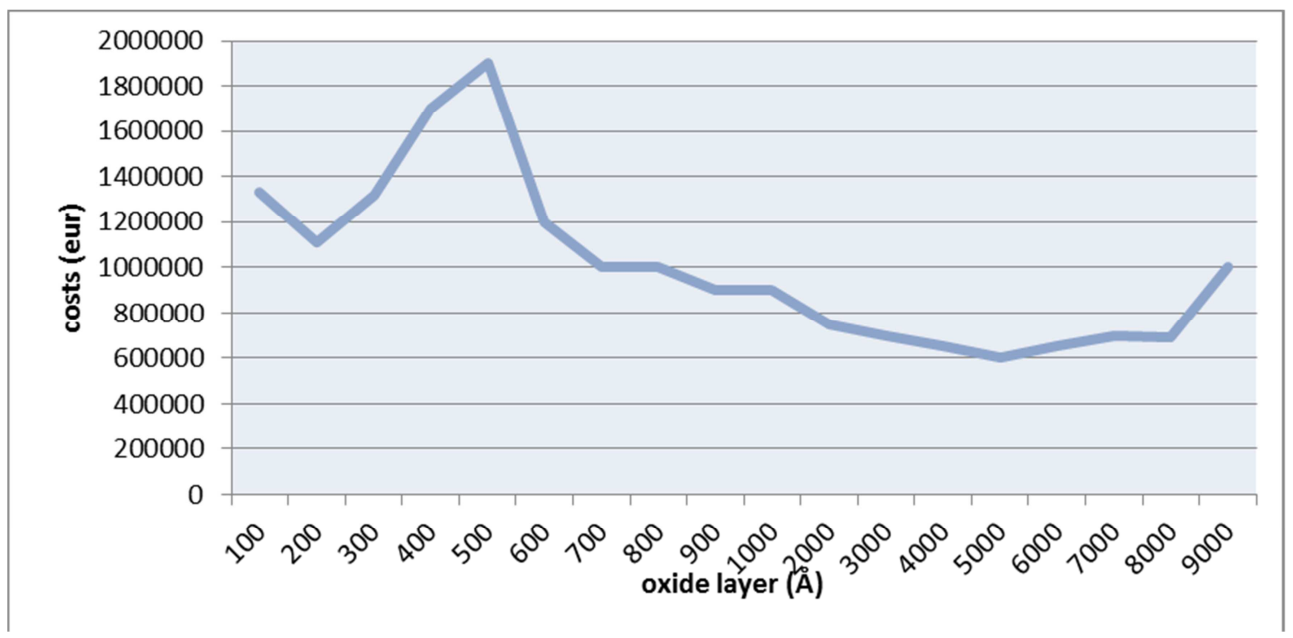

Figure 4 - Investment costs of technology (Source: own processing)

\section{3-DIMENSIONAL MODEL OF INTEGRATED COST OF IMPROVEMENT}

Problem of two - dimensional representation of the correlation between the cost and the oxide layer lies in the fact that each change of curve progress is necessary to explain separately and the estimation of values between the individual stages is relatively little accurate. Estimation accuracy is increased in case that the cost curve is getting close to some, for example by experiment defined value that represents, from particular viewpoint, optimum. In Fig. 5 we have presented three - dimensional surface representing the model of cost function of integrated improvement, calculated per unit of production.

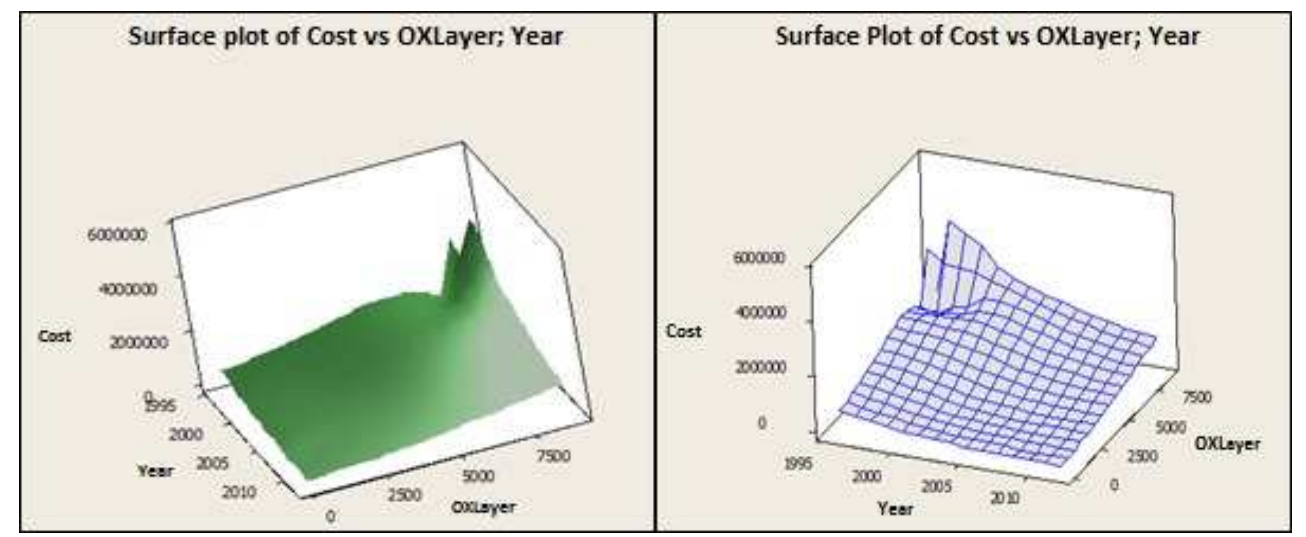

Figure 5-3-dimensional model of the cost function of integrated improvement 


\section{CONCLUSION}

The ability to estimate the costs associated with improvement of processes as well as possible before approving the project improvement itself, allows the company's responsible manager to make the right decisions in relation to the approval, followed by management, as well as the completion of process of improvement. When improving the processes, it is generally difficult to estimate future profit expected after the improvement. Although such an assessment is often done only in general terms, it is necessary for each improvement relatively accurately estimate the expected costs associated with the improvement.

In the present publication, a method for modelling the improvement process, by an integrated manner, is proposed. It is a method in which are considered the basic attributes of the improvement in quality, safety and environment, synergistically combined in the same improvement project. The work examines the use of sophisticated quantitative, especially statistical methods for determining the most accurate estimation of the costs associated with improving processes. Model is based on known methods for modelling the Costs of continuous quality improvement, safety and environment. It connects these costs into one function connected to the basic parameter of improvement, i.e. parameter, which is the subject of the improvement in the process.

\section{REFERENCES}

Asif, M., Fisscher O.A.M, de Bruijn E.J. and Searcy, C., 2010. Metamanagement of integration of management systems. The TQM Journal, 22(6), pp.570-582.

Douglas A. and Glen D., 2000. Integrated management systems in small and medium enterprises. Total Quality Management, 11(4/5\&6), pp.686-690.

Griffith A., 2000. Integrated management systems: a single management system for project control? Eng Construct Architect Manag. 7, pp.232-240.

Jonker J. and Karapetrovic S., 2004. Systems thinking for the integration of management systems. Business Process Management Journal, 10(6), pp.608615 .

Jørgensen T.H., Remmen A. and Mellado, M.D., 2006. Integrated Management systems - three different levels of integration. Journal of Cleaner Production, Vol. 14, pp.713-722.

Karapetrovic S., 2002. Strategies for the integration of management systems and standards. The TQM Magazine, 14(1), pp.61-67.

Karapetrovic S., 2003. Musings on integrated management systems. Measuring Business Excellence, 7(1), pp.4-13. 
Karapetrovic, S. and Willborn, W., 1998. The system's view for clarification of quality vocabulary. International Journal of Quality \& Reliability Management 15(1), pp.99-120.

Karapetrovic, S. and Jonker, J., 2003. Integration of standardized management systems: searching for a recipe and ingredients. Total Quality Management, 14(04), pp.451-459.

McDonald, M., Mors, T.A. and Phillips, A., 2003. Management system integration: Can it be done? Quality Progress, 36(10), pp.67-74.

Rocha M., Searcy C. and Karapetrovic S., 2007. Integrating Sustainable Development into Existing Management Systems. Total Quality Management \& Business Excellence, 18(1-2), pp.83-92.

Salomone R., 2008. Integrated management systems: experiences in Italian organizations. Journal of Cleaner Production, 16(16), November 2008, pp.1786-1806.

Wilkinson G. and Dale B.G., 1999. Integrated management systems: an examination of the concept and theory. The TQM Magazine, 11(2), pp.95-104.

Wilkinson G. and Dale B.G., 2001. Integrated management systems: a model based on a total quality approach. Managing Service Quality, 11(5), pp.318-330.

Wilkinson G. and Dale B.G., 2002. An examination of the ISO 9001:2000 standard and its influence on the integration of management systems. Production Planning \& Control: The Management of Operations, 13(3), pp.284-297.

Zutshi A. and Sohal A. S., 2005. Integrated management system: The experiences of three Australian organisations. Journal of Manufacturing Technology Management, 16(2), pp.211-232.

\section{ABOUT THE AUTHOR}

Assoc. Prof. RNDr. Zuzana Hajduová, PhD. - University of Economics in Bratislava, Faculty of Business Economy, Tajovského 13, Košice, 04130 , Slovakia, e-mail: zuzana.hajduova1 @ gmail.com 